\title{
Psychological Well-Being pada Mantan Penderita Skizofrenia
}

\author{
Andriana Budi Riastri ${ }^{1}$ \\ Fakultas Psikologi, Program Studi Magister Psikologi \\ Universitas 17 Agustus 1945 Surabaya \\ andriana_s2@untag-sby.ac.id \\ Suryanto ${ }^{2}$ \\ Fakultas Psikologi Universitas Airlangga Surabaya \\ suryanto@psikologi.unair.ac.id \\ IGAA.Noviekayati ${ }^{3}$ \\ Fakultas Psikologi, Program Studi Magister Psikologi \\ Universitas 17 Agustus 1945 Surabaya \\ noviekayati@untag-sby.ac.id
}

\begin{abstract}
The presence of clinical status and treatment programs or interventions has an important impact that determines the quality of long-term life for them. The purpose of this study was to describe the psychological well-being of former schizophrenics. This research uses a qualitative approach with the draft case study, the subject of research is a former patient of schizophrenia people, and the method of data collection used is observation, interviews and documentation. The data obtained is analyzed through three phases including data reduction, data presentation, and data verification in the form of thematic analysis with the coding of the interview transcript that has been made verbatim. There are six dimensions of psychological well-being, i.e. self-acceptance, positive relationship with others, personal growth, life purpose, environmental mastery and autonomy.
\end{abstract}

Kata kunci: Asylum, Psychological Well-being, Skizophrenia, Well-being.

\begin{abstract}
Abstrak
Adanya status klinis yang meliputi program pengobatan dan intervensi memiliki dampak penting yang menentukan kualitas hidup jangka panjang bagi penderita skizofrenia. Tujuan dari penelitian ini adalah untuk mendeskripsikan kesejahteraan psikologis pada mantan penderita skizofrenia Penelitian ini menggunakan pendekatan kualitatif dengan rancangan studi kasus, subjek penelitian adalah mantan pasien rumah sakit jiwa penderita skizofrenia rumah sakit jiwa menur surabaya, metode pengumpulan data yang digunakan adalah observasi, wawancara dan dokumentasi. Terdapat enam dimensi psychological well-being, yaitu penerimaan diri, hubungan positif dengan orang lain, pertumbuhan pribadi, tujuan hidup, penguasaan lingkungan dan otonomi.
\end{abstract}

Kata kunci: Kesejahteraan, Kesejahteraan Psikis, Rumah sakit jiwa, Skizofrenia. 


\section{PENDAHULUAN}

Dewasa ini jumlah penderita gangguan jiwa semakin banyak terutama skizofrenia. Jumlah penderita gangguan jiwa di Kota Surabaya terus melonjak. Makin tingginya beban hidup yang harus ditanggung sebagian warga Surabaya ternyata berdampak pada meningkatnya jumlah penderita gangguan jiwa. Sebuah temuan baru menyatakan, di Surabaya Timur saja, dalam tiga tahun terakhir tercatat ada sedikitnya 120 penderita gangguan jiwa baru. Angka tersebut muncul dari hasil pemeriksaan para tenaga psikolog di Puskesmas Rangkah, Tambaksari. Itu belum termasuk jumlah penderita gangguan jiwa di wilayah Surabaya yang lain. Instalasi Rawat Inap (Irna) Jiwa RSU dr Soetomo setidaknya setiap bulan ada 20-30 pasien baru menjalani rawat inap dari tahun sebelumnya yang hanya 10-20 pasien per bulan. Dari jumlah pasien itu, $80-90 \%$ merupakan penderita skizofrenia (dalam http://www.surabayapost.co.id/).

Skizofrenia merupakan gangguan mental kronik, pervasif, dan bersifat kambuhan yang umumnya menyerang seseorang pada usia produktif serta merupakan penyebab utama disabilitas pada kelompok usia 15-44 tahun (Kring, 2012). Pada umumnya beberapa gangguan dialami oleh penderita skizofrenia, seperti gangguan pada proses berpikir, gangguan dalam mengendalikan emosi, gangguan perilaku, dan gangguan yang berkaitan dengan penurunan fungsi pada otak yang berhubungan dengan kemampuan atensi, konsentrasi, kalkulasi, pengambilan keputusan atau sering disebut dengan disfungsi kognitif. Gangguan yang dialami oleh penderita skizofrenia membuat penderita skizofrenia mengalami hambatan dalam melakukan aktivitas yang berhubungan dengan pekerjaan, kemampuan bersosialisasi, kemampuan untuk merawat diri dan banyak bidang lainnya yang tidak mampu dilakukan secara optimal seperti manusia normal pada umumnya. Menurut data dari WHO, Amerika Serikat maupun Epidemological Cathment Area (ECA) dijelaskan bahwa prevalensi penderita skizofrenia berkisar antara 1\% hingga 1,5\% sehingga penderita yang memiliki gangguan skizofrenia dapat ditemukan pada hampir seluruh bagian dunia (Sadock dan sadock, 2010). Prevalensi gangguan jiwa berat di Indonesia diketahui sebanyak 1,7\% dari seribu orang (Riset Kesehatan Dasar Indonesia, 2013), Propinsi jawa timur diketahui menyumbang jumlah penderita skizofrenia yang cukup banyak sehingga berada pada peringkat ke-7 dari beberapa daerah di indonesia. Selama ini cara penerimaan masyarakat terhadap penderita skizofrenia dilakukan dengan penuh penolakan, disebabkan oleh kurangnya pengetahuan keluarga maupun masyarakat terhadap perawatan bagi penderita skizofrenia. Stigma negatif yang diberikan oleh keluarga maupun masyarakat yang menggangap bahwa salah satu seorang anggota keluarganya 
menderita skizofrenia merupakan aib bagi keluarga, sehingga penderita disembunyikan bahkan dikucilkan dan tidak dibawa berobat ke dokter karena merasa malu bahkan di beberapa daerah di Indonesia sebagian dari penderita skizofrenia bahkan sampai dipasung atau dikurung di suatu ruangan dalam keadaan terikat tangan dan kakinya sehingga menurut Sykes (2010) penderita skizofrenia kehilangan rasa kemerdekaannya seperti hilangnya hubungan heteroseksual (loss of heterosexual), hilangnya kebebasan (loss of autonomy), hilangnya pelayanan (loss of good and service), dan hilangnya rasa aman (loss of security) serta munculnya rasa sakit yang diakibatkan oleh munculnya prasangka buruk (stigmatizasi) dari masyarakat (dalam Susanti dan Maryam, 2013).

Kesejahteraan psikologis terutama bagi mantan penderita skizofrenia merupakan suatu kondisi dimana individu tersebut mempunyai kemampuan untuk menetukan pilihan atas dirinya, memiliki kapasitas untuk mengatur lingkungan dan kehidupannya secara efektif, memiliki hubungan yang positif dengan orang lain, meyakini bahwa hidupnya bermakna dan memiliki tujuan, pertumbuhan dan pengembangan diri yang positif, dan memiliki kemampuan untuk menerima diri baik masa lalu maupun kehidupan yang saat ini dijalani ( Iriani \& Ninawati, 2015). Akan tetapi kesejahteraan psikologis tersebut menjadi sulit tercapai karena penderita skizofrenia secara tidak langsung mendapat penolakan, isolasi dan pandangan yang cenderung negatif di masyarakat meskipun penderita tersebut sudah dinyatakan cukup sehat perilaku dan mentalnya oleh pihak rumah sakit jiwa. Adanya dukungan sosial dari anggota keluarga dan masyarakat dapat berfungsi sebagai strategi preventif untuk munculnya stress dan perilaku yang negatif seperti sebelumnya. Johnson dan Johnson (dalam Ermayanti \& Abdullah, 2011) menyebutkan bahwa dengan adanya penghargaan yang positif dari keluarga akan membantu individu untuk meningkatkan rasa percaya dirinya, hal itu juga berlaku bagi mantan pasien skizofrenia. Menurut Yudianto (2011), perasaan bahagia serta adanya kepuasan hidup dan realisasi diri inilah yang disebut dengan psychological well-being.

Teori Psychological well-being dikembangkan oleh Ryff (dalam Maryam, 2013) yang merujuk pada perasaan seseorang mengenai aktivitas hidup sehari-hari, yang dalam proses aktivitas tersebut mengalami fluktuasi pikiran dan perasaan yang dimulai dari kondisi mental negatif sampai pada kondisi mental yang positif. Seperti contohnya, trauma pada seseorang juga salah satu bentuk fluktuasi dari kondisi mental negati. Menurut Ryff (dalam Maryam , 2013) dijelaskan bahwa secara psikologis manusia yang memiliki sikap positif terhadap diri dan orang lain adalah manusia yang mengakui dan menerima aspek yang ada dalam dirinya, baik yang bersifat baik maupun buruk serta merasa positif dengan kehidupan masa lalunya, 
memiliki relasi positif dengan orang lain, mampu melakukan dan mengarahkan perilaku secara mandiri dengan penuh keyakinan diri (otonomi), dapat melakukan sesuatu bagi orang lain, memiliki tujuan hidup, dapat mengembangkan potensi diri sesuai dengan kapasitas yang dimiliki, serta mampu mengambil peran aktif dalam memenuhi kebutuhannya melalui lingkungan.

Psychological well-being berhubungan dengan kepuasan pribadi, keterikatan, harapan, rasa syukur, stabilitas suasana hati, pemaknaan terhadap diri sendiri, harga diri, kegembiraan, kepuasan, dan optimisme, termasuk juga mengenali kekuatan dan mengembangkan bakat dan minat yang dimiliki (Bartram \& Boniwell, dalam Faturochman, 2012). Dikemukakan oleh Ryff (dalam Moningka, 2013) terdapat enam buah dimensi dari psychological well being, yaitu : 1) Penerimaan Diri (Self Acceptance), yakni bagaimana individu yang dapat menerima dirinya dan pengalamannya, 2) Hubungan Positif dengan Orang Lain (Positive Relations with Others), yang mengacu pada bagaimana individu memiliki hubungan positif dan membina kepercayaan kepada orang lain, 3) Pertumbuhan Pribadi (Personal Growth) yang mengacu pada individu yang memiliki kesadaran akan potensi yang dimiliki, adanya keinginan untuk terus berkembang, tertarik pada pengalaman-pengalaman baru, merasakan kemajuan diri dari waktu ke waktu, serta fleksibel dalam berubah ke arah yang positif dengan cara yang efektif untuk menjadi sosok pribadi yang lebih baik, 4) Tujuan Hidup (Purpose in Life), mengacu pada individu yang memiliki tujuan hidup seperti memiliki nilai-nilai yang diyakini dapat memberinya arti dan tujuan hidup, memiliki pemahaman yang jelas akan tujuan dan arah hidup yang dijalani, memiliki arah dalam hidupnya, merasakan makna kehidupannya saat ini maupun masa lalunya, 5) Penguasaan Lingkungan (Environmtal Mastery) yaitu dimana individu mampu menguasai dan mengatur lingkungan, mengontrol berbagai kegiatan eksternal yang kompleks, menggunakan kesempatan yang ada secara efektif, serta mampu memilih atau menciptakan konteks yang sesuai dengan kebutuhan-kebutuhan dan nilai-nilai yang dianut, dan 6) Otonomi (Autonomy), yang mengacu pada individu mampu mandiri dan mengarahkan dirinya sendiri, mampu menghadapi tekanan sosial dengan berpikir dan berperilaku dalam beberapa hal, dapat mengatur tingkah laku dari dalam diri, dan mengevaluasi diri nilai-nilai pribadi.

Berdasarkan penelitian terdahulu yang dilakukan oleh Akbar (2013) tentang Psychological well-being pada orang dengan skizofrenia diketahui bahwa pada hasil analisis pada dimensi penerimaan diri subjek menerima keadaannya karena memiliki riwayat keluarga yang memiliki gangguan serupa dan pada dimensi yang lainnya pun subjek mengalami 
kesusahan pada dimensi penguasaan lingkungan. Sedangkan pada penelitian yang dilakukan oleh Widianti, dkk (2018) yang meneliti tentang gambaran kesejahteraan psikologis pada family caregiver orang dengan skizofrenia diketahui bahwa tingkat kesejahteraan psikologis secara keseluruhan dikategorikan sedang dengan prosentase $84,9 \%$ dari seluruh responden dengan dimensi yang paling tinggi pada dimensi penguasaan lingkungan.

\section{METODE}

Metode penelitian yang digunakan dalam penelitian ini adalah pendekatan kualitatif dengan tipe penelitian studi kasus instrinsik. Unit analisis dalam penelitian ini adalah psychological well being mantan penderita skizofrenia. Subjek penelitian ini melibatkan dua orang berjenis kelamin laki-laki mantan penderita skizofrenia RSJ Menur Surabaya berusia diatas 18 tahun. Selain menggali data dari kedua subjek utama, penelitian ini juga menggali data dari significant other dari keluarga terdekatnya. Teknik penggalian data yang digunakan dalam penelitian ini adalah teknik wawancara. Metode wawancara yang digunakan dalam penelitian ini adalah wawancara mendalam atau depth interview, yakni untuk memperoleh pemahaman secara menyeluruh dan mendalam mengenai hal-hal yang berkaitan dengan bagaimana psychological well being mantan penderita skizofrenia. Proses pengorganisasian dan analisis data dimulai dengan mengorganisasikan data terlebih dahulu. Dengan data yang beragam, penulis mengorganisasikan data dengan rapi, sistematis dan selengkap mungkin (Poerwandari, 2011). Teknik analisis data yang digunakan dalam penelitian ini adalah analisis tematik dengan pendekatan theory driven dimana pengembangan tematik dilakukan berdasarkan teori milik Ryff (dalam Maryam, 2013).

\section{HASIL DAN PEMBAHASAN}

Pada dimensi penerimaan Diri (Self-Acceptance), perilaku skizofren yang dialami oleh subjek I menyebabkan dimensi penerimaan dirinya kurang positif dari subjek lainnya. Subjek I belum memiliki sikap yang positif terhadap dirinya sendiri karena sering merasa kecewa, menganggap dirinya tidak berharga dan merasa orang lain tidak akan menghargai dirinya karena perilaku negatif yang dilakukannya. Subjek I juga belum memiliki perasaan dan pandangan yang positif pada pengalaman masa walaupun akhirnya subjek I hanya pasrah dan berusaha menerima. Subjek I mampu mengenali kelemahan dalam dirinya, subjek merasa dirinya adalah mudah tersulut emosi dan kurang mendekatkan diri kepada tuhan sehingga mudah frustasi namun subjek tidak mampu mengenali kelebihan yang dimilikinya. Sedangkan 
pada dimensi yang sama, penerimaan diri subjek II lebih positif daripada subjek I, mampu menerima keadaan masa lalu dan subjek II menyesali walaupun akhirnya subjek II berusaha untuk menerima dan mengambil hikmah pengalaman masa lalunya. subjek II mampu mengenali kelemahan dan kelebihan dalam dirinya. Kelemahan dalam dirinya adalah subjek adalah pribadi yang introvert dan suka memendam perasaannya sedangkan Kelebihan dalam dirinya subjek adalah orang yang sayang dengan keluarga dan selalu mengalah dan selalu melakukan intropeksi diri.

Pada dimensi hubungan baik dengan orang lain (Possitive Relations with Others) yang dialami oleh subjek I yaitu karena adanya pengalaman kekerasan yang pernah dialami oleh salah satu orang tuanya sehingga menjadi pemicu awal yang menyebabkan subjek I kurang baik dalam membina hubungan positif dan membangun kepercayaan dengan orang lain. Subjek I lebih menutup diri dengan orang yang tidak dikenalnya, takut berhubungan dekat dengan orang baru karena pengalaman kekerasan dalam keluarga yang dialami oleh seorang anggota keluarganya. Subjek I lebih memiliki hubungan yang hangat, dekat, harmonis dan saling percaya dengan ibunya setelah ayah subjek meninggal. Subjek I lebih berani menceritakan masalah pribadinya kepada ibu dan adik subjek ketika subjek sedang ada masalah dan tertekan. Subjek I lebih mampu menjalin keakraban dan menikmati interaksi baik melalui percakapan atau aktivitas bersama ibu dan adik subjek daripada dengan orang lain. Pada subjek II, banyaknya tekanan yang diterima pada usia yang relatif masih muda membuat subjek rentan mengalami depresi yang berulang sehingga menyebabkan subjek akhirnya didiagnoosa sebagai penderita skizofrenia / orang dengan skizofrenia (ODS). Subjek II memiliki hubungan positif dengan orang lain lebih positif dari subjek sebelumnya. Setelah sembuh dari skizofrenia, subjek II lebih memiliki hubungan yang hangat, dekat, dan saling percaya dengan kakak dan orang tua subjek. Subjek II lebih berani menceritakan masalah pribadinya kepada kakak, ibu dan ayah subjek. Subjek II juga mampu memberikan bantuan kepada teman yang mempunyai masalah dan selalu ada saat temannya membutuhkan. Subjek II lebih mampu menjalin keakraban dan menikmati interaksi baik melalui percakapan atau aktivitas bersama kakak dan ibu subjek.

Pada dimensi pertumbuhan pribadi (Personal Growth), subjek I merasa bingung dengan potensi apa yang dimilikinya. Pengalaman menjadi penderita skizofrenia membuat subjek I memiliki keinginan untuk terus berkembang dengan menjadikan pengalaman masa lalu pembelajaran dan ingin menjadi orang yang lebih baik. Subjek I juga merasakan peningkatan dalam dirinya yaitu lebih banyak melakukan kegiatan-kegiatan yang lebih positif dan mulai jarang berfikir yang terlalu berat, subjek juga lebih bertanggung jawab dalam pekerjaannya. 
Bagi subjek I pengalaman baru adalah suatu hal yang penting dan merasa tertantang dengan pengalaman baru karena dapat menambah wawasan. Sedangkan pada subjek II untuk dimensi yang serupa sudah mampu mengenali potensi dirinya yaitu memasak dan dan otak-atik mesin motor. Subjek II mengasah kemampuan dengan membantu ibu dan bapaknya dirumahyang mempunyai usaha warung makan dan tempat servis motor kecil-kecilan. Selain itu subjek juga sering membantu pekerjaan di salah satu hotel ternama di kota Surabaya sebagai pekerja freelance. Hal tersebut membuat subjek II memiliki keinginan untuk terus berkembang dengan memotivasi dirinya untuk menjadi lebih baik dan selalu sehat. Subjek II juga merasakan peningkatan dalam dirinya yaitu lebih detail dengan memperhatikan hal-hal yang kecil, memperhatikan kebersihan dan penampilan setelah dinyatakan sembuh serta lebih mendekatkan diri dengan Tuhan karena pengalaman menjadi penderita skizofrenia. Bagi subjek II, pengalaman baru adalah suatu hal yang penting.

Pada dimensi tujuan hidup (Purpose in Life), subjek I cenderung kurang mampu menjelaskan tujuan-tujuan yang ingin dicapai setelah menjadi mantan pasien skizofrenia. Adanya anggapan bahwa orang lain dan masyarakat tidak mau menerima keberadaannya karena sewaktu-waktu takut kambuh dan membuat cemas orang lain sehingga subjek terkesan menjauh apabila dengan orang yang baru dikenal karena takut dibahas masa lalunya yang pernah menderita skizofrenia. Sedangkan terdapat perbedaan pada subjek II dalam dimensi tersebut, yakni subjek II memiliki tujuan hidup baik dengan gambaran bahwa subjek II ingin bekerja atau berdagang agar memiliki kegiatan sehingga pikirannya teralihkan dan bisa hidup normal seperti individu yang lainnya. Walaupun subjek mengetahui bahwa orang lain akan menemukan masa lalunya sebagai mantan penderita skizofrenia namun subjek II tidak merasa malu karena menurutnya tidak pernah merugikan orang lain dan harapannya saat ini adalah ingin bekerja agar penghasilannya bisa untuk membantu orang tua sehingga subjek II dinilai lebih positif perilakunya dalam memberikan makna hidup.

Pada dimensi penguasaan lingkungan (environmental mastery), subjek I dalam kesehariannya hanya berkutat di rumah bersama ibunya, meski terkadang ikut membantu pamannya di toko namun subjek I lebih banyak diam, cuek dengan keadaan orang lain dan kurang mampu mengubah kebiasaannya seperti bangun siang. Subjek I kurang dapat memiliki kontrol dan penguasaan diri terhadap lingkungan dan kebiasaannya sehari-hari sehingga pada aspek ini subjek I dinilai negatif dalam penguasaan lingkungan. Pada subjek II, selain dirumah membantu orang tuanya yang memiliki warung kecil juga terkadang bekerja paruh waktu di sebuah hotel apabila diperlukan (event). Subjek II suka bersih-bersih dan membereskan 
rumahnya apabila tidak sedang mendapat kerja panggilan paruh waktu sambil membantu orang tuanya sehingga pada aspek ini subjek II dinilai lebih positif dari subjek I dalam penguasaan lingkungan yang baik.

Pada dimensi terakhir yaitu dimensi Otonomi (autonomy), subjek I sudah memiliki otonomi yang baik terlihat dari kebiasaan subjek yang mampu mengurus dirinya dan memahami apa saja kebutuhannya sehingga pada aspek ini subjek dinilai memiliki otonomi yang baik karena sudah tidak bergantung pada orang lain. Sedangkan pada subjek II, dinilai juga memiliki otonomi yang baik karena sejak kecil sudah terbiasa mandiri dalam mengurus diri terutama saat ini ibunya juga sedang sakit sehingga subjek pun mampu mengurus ibunya dengan baik. Dalam interaksi sosialnya, subjek II masih memiliki banyak teman dan masih dipercaya bekerja paruh waktu apabila dibutuhkan sewaktu-waktu meskipun rekan-rekan kerjanya mengetahui bahwa subjek II adalah mantan penderita skizofrenia. Hal tersebut terjadi karena subjek II dinilai oleh rekan-rekan kerjanya sebagai pribadi yang cekatan dan memiliki keahlian yang baik dalam melayani tamu undangan ketika ada event di hotel tempatnya bekerja.

\section{SIMPULAN}

Psychological Well Being merupakan evaluasi individu terhadap kepuasan hidup dirinya dimana di dalamnya terdapat penerimaan diri, baik kekuatan dan kelemahannya, memiliki hubungan yang positif dengan orang lain, memiliki otonomi, dapat menguasai lingkungan, memiliki tujuan dalam hidup serta memiliki pertumbuhan pribadi. Berdasarkan analisa pada setiap enam dimensi dari Psychological Well Being disimpulkan bahwa pada kedua subjek pada dimensi penerimaan diri (self-acceptance) masih belum memiliki sikap positif terhadap diri sendiri, hal ini dikarenakan persepsi stigma yang muncul bagi penderita skizofrenia tidak akan mudah diterima oleh masyarakat sehingga kedua subjek cenderung menarik diri dan merasa insecure atas kondisi yag dialaminya. Pada dimensi hubungan positif dengan orang lain, kedua subjek sudah mampu berinteraksi dengan cukup baik dan menjalin keakraban baik melalui percakapan atau ketika melakukan aktivitas bersama-sama. Kedua subjek juga memiliki keinginan untuk terus berkembang dan merasakan adanya peningkatan kearah yang positif dalam diri mereka dari waktu ke waktu pada dimensi pertumbuhan pribadi. Kedua subjek juga mampu menciptakan konteks dan memilih lingkungan yang sesuai dengan kebutuhan atau nilai-nilai pribadi masing-masing subjek sebagai mantan penderita skizofrenia. Pada dimensi otonomi, kedua subjek mampu melakukan evaluasi dirinya dan berperilaku 
dengan menggunakan nilai-nilai pribadi yang dimiliki. Saran dari penelitian ini adalah bagi keluarga penderita disarankan menerima dan memberi dukungan terhadap keluarga yang menderita gangguan jiwa terutama dukungan emosional agar penderita merasa keberadaanya selain itu keluarga penderita memberikan pelatihan sosial agar keluarga yang menderita mampu membuat hubungan sosial yang baik serta menambah wawasan dan bagi peneliti selanjutnya coba bandingkan kondisi psychological well being pada beberapa subjek agar subjek lebih variatif dalam arti jenis skizofrenia yang dialami subjek, usia, jenis kelamin, ras, agama dan status sosial ekonomi. Dengan demikian kondisi psychological well being mantan penderita skizofrenia dapat dikatakan mengarah ke arah yang positif.

\section{DAFTAR PUSTAKA}

Allison, D. B., Mackell, J. A., \& McDonnell, D. D. (2003). The impact of weight gain on quality of life among persons with schizophrenia. Psychiatric Services, 54(4), 565-567. https://doi.org/10.1176/appi.ps.54.4.565

Ambari, P.K.M. (2010).Hubungan Antara Dukungan Keluarga Dengan Keberfungsian Sosial Pada Pasien Skizofrenia Pasca Perawatan Di Rumah Sakit. Fakultas Psikologi Universitas Diponegoro Semarang.

Arif.I.S. (2006). Skizofrenia Memahami Dinamika Keluarga Pasien. PT Refika Aditama Azwar, S. (2007). Metode penelitian. Yogyakarta: Pustaka Pelajar.

Callahan, R.M., Tolman, R.M., \& Saunders. D.G. (2003). Adolescent Dating Violence Victimization and Psychological Well-Being. Journal of Adolescent Research, 18 (2), 664-681.

Carla R. M., Sumarni P., \& Lusia P.W. (2008). Hubungan Antara Ekspresi Emosi Keluarga Pasien Dengan Kekambuhan Penderita Skizofrenia Di Rs Dr.Sardjito Yogyakarta. Berita Kedokteran Masyarakat Vol. 24, No. 4

González-Torres, M. A., Oraa, R., Arístegui, M., Fernández-Rivas, A., \& Guimon, J. (2007). Stigma and discrimination towards people with schizophrenia and their family members: A qualitative study with focus groups. Social Psychiatry and Psychiatric Epidemiology, 42(1), 14-23. https://doi.org/10.1007/s00127-006-0126-3

Hardjo, S., \& Novita, E. (2017). Hubungan antara dukungan sosial dengan psychological wellbeing pada remaja korban sexual abuse. Analitika, 7(1), 12-19. Retrieved from https://pdfs.semanticscholar.org/aa5a/2936e999b7f56c6b623a23d1f7974647521c.pdf 
Hawton, K., Sutton, L., Haw, C., Sinclair, J., Deeks, J. J., Ton, K. H. A. W., ... Deeks, J. J. (2013). Schizophrenia and suicide : systematic review of risk factors Schizophrenia and suicide : systematic review of risk factors. 9-20. https://doi.org/10.1192/bjp.187.1.9

Makin Banyak Orang Gila Baru di Surabaya(2011, 11 Oktober). Surya online. Diakses 6 juni 2019 dari http://surabaya.tribunnews.com/

Moleong L. J. (2017). Metode Penelitian Kualitatif. Bandung edisi Revisi : PT. Raja Rosdakarya.

Pasien Gangguan Jiwa Terus Meningkat (2011, 12 November).Surabayapost online. Diakses 10 April 2019 dari http://www.surabayapost.co.id/

Permatasari, L., Sriati, A., \& Widiastuti, M. (2012). Gambaran dukungan sosial yang diberikan keluarga dalam perawatan penderita skizofrenia di instalasi rawat jalan rumah sakit jiwa provinsi jawa barat. 1-15. http://jurnal.unpad.ac.id

Poegoeh, D. P., \& Hamidah, H. (2016). Peran Dukungan Sosial Dan Regulasi Emosi Terhadap Resiliensi Keluarga Penderita Skizofrenia. INSAN Jurnal Psikologi Dan Kesehatan Mental, 1(1), 12. https://doi.org/10.20473/jpkm.v1i12016.12-21

Poerwandari, E. K. (2011). Pendekatan Kualitatif Untuk Penelitian Perilaku Manusia. Jakarta: Lembaga (LPSP3) UI

Qudwatunnisa, F., Yamin, A., \& Widianti, E. (2018). Gambaran Kesejahteraan Psikologis Pada Family Caregiver Orang Dengan Skizofrenia Di Instalasi Rawat Jalan Grha Atma Bandung. NurseLine Journal, 3(1), 21-29.

Ramadhani, T., Djunaedi, D., \& Sismiati S., A. (2016). KESEJAHTERAAN PSIKOLOGIS (PSYCHOLOGICAL WELL-BEING) SISWA YANG ORANGTUANYA BERCERAI (Studi Deskriptif yang Dilakukan pada Siswa di SMK Negeri 26 Pembangunan Jakarta). Insight: Jurnal Bimbingan Konseling, 5(1), 108. https://doi.org/10.21009/insight.051.16

Van Dierendonck, D., Díaz, D., Rodríguez-Carvajal, R., Blanco, A., \& Moreno-Jiménez, B. (2008). Ryff's six-factor model of psychological well-being, a Spanish exploration. Social Indicators Research, 87(3), 473-479. https://doi.org/10.1007/s11205-007-91747 